\title{
THE ANCIENT ART OF FEELING THE PULSE
}

BY

\author{
D. EVAN BEDFORD
}

Clinical Assistant to Dr. John Parkinson, National Heart Hospital, 1924-33

Paterson Research Scholar, Cardiac Department, London Hospital, 1926-28

Based on a paper read before the Osler Club, 1949

The Ars Sphygmica or ancient science of the pulse dates back into antiquity to long before Galen's time. It is probable that Chinese and Hindu physicians were skilled in feeling the pulse before the dawn of Hippocratic Medicine, and Oriental pulse-lore appears to have developed quite independently of Greek influence.

\section{Chinese SPHYGMOLOGY}

According to legend, Chinese sphygmology was founded by the Emperor Hoamti who is said to have been the author of several books on the pulse about 2500 B.C., and to have been very skilled in the art. Knowledge of Chinese pulse-lore was first brought to Europe by Jesuit missionaries, one of whom, Father Boym, translated the books of Wang-cho-ho on the pulse in 1652, and this translation was published by Cleyer in 1682 in an illustrated Latin work. I have not seen Cleyer's book, but I possess the French translation of Wang-cho-ho's Secret of the Pulse, by Father Hervieu, published in du Halde's Description of the Chinese Empire, and good accounts of the Chinese pulse doctrines are given by Floyer (1707), Menuret (1768), and especially by Ozanam (1886). Wangcho-ho lived during the Tsin dynasty, several centuries B.C., and he refers to other works on the pulse both ancient and modern.

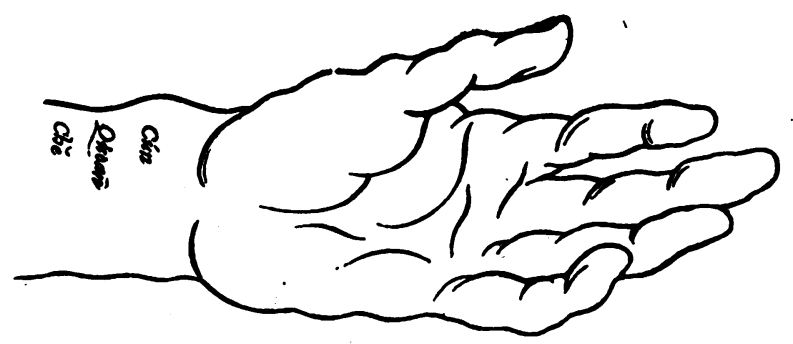

Fig. 1.-Chinese pulses after Cleyer. (1) Cun corresponds to upper part of body, palpated by ring finger. (2) Quoan, middle part of body, middle finger. (3) Che, lower part of body, index finger (from Ozanam).

The Chinese physician visited his patient in the morning, before taking food, when free from all cares and distractions, and he was enjoined to banish all other thoughts from his mind in order to concentrate on the pulse. This was important because the pulse was timed by the respiration of the physician, four pulsations to each respiration being the natural rate in adults. The patient's arm having been placed on a cushion, the pulse was then palpated at three separate places by the physician's index, ring and middle fingers respectively (Fig. 1). At each site, light, moderate, and firm pressure was applied in turn so as to elicit the superficial and deep pulses. The pulse was examined at both wrists, the physician using his left hand for the patient's right pulse, and vice 
versa. All the permutations of these six pulses could not be hastily interpreted, and we may well believe that the whole performance occupied several hours.

Each organ had its proper pulse and different organs prevailed at different seasons. When a particular pulse appeared at the wrong place or in the wrong season, a serious disequilibrium of the system was indicated. For example, in spring the pulse of the liver normally predominated, and to have the pulse of the lung at this season was mortal; to have the pulse of the heart was less serious as the heart was regarded as the son of the liver. Thus to judge the pulse it was necessary to know not only the pulse appropriate to each organ but also the official pulse calendar. Prognosis was determined with great precision from the pulse and there were no less than 16 pulses indicating death within periods of 24 hours up to 5 years. Indeed, a virtuoso of the pulse such as Hoamti was reputed to have been able to forecast the time of death as far ahead as 30 to 35 years!. Pregnancy could be detected by the pulse before other signs appeared, so that there was no need for an Aschheim-Zondek test in those days and, moreover, the sex of the unborn child could be determined, as later Avicenna professed to do.

The various pulses were represented graphically by symbols or hieroglyphs representing, for example, the jump of a frog, the tail of a fish, drops of rain falling on a roof, and so on. While relying mainly on the pulse, Chinese physicians also studied the patient's features and complexion and, sometimes, they inspected the urine as became customary in Europe in medieval times. It was not necessary to interrogate the patient, as the symptoms, the organ affected, and the prognosis could be decided entirely from the pulse. Chinese sphygmology was certainly not founded on clinical observation, and amounted to little more than a mystical practice which was handed down as a carefully guarded secret. In so far as it involved a determination of the diagnosis, prognosis, and treatment from the pulse alone, it does not differ in principle from the Greek and Arabian doctrines, and we may note in it the germ of later ideas such as the organic pulses.

\section{INDIAN SPHYGMOLOGY}

The art of feeling the pulse was highly developed amongst the ancient Hindu physicians who, like the Chinese, dated their pulse-lore back to a mythological antiquity. Susruta (5th century A.D.), the Indian Galen, though most renowned for his surgery, is depicted feeling the pulse in Fig. 2. Some account of Hindu sphygmology is given by Wise (1845) and by Gupta (1901), and I have the English translation of a Sanscrit work on the pulse by Sage Kanad, published in Calcutta in 1891.

Like the Chinese; the Hindus laid great stress on not only the patient but also the physician being at ease. Thus Sage Kanad said that the time for feeling the pulse was " in the morning when both the physician and the patient, after performing their respective morning duties, are comfortably settled; the former should feel the pulse of the latter." The pulse was felt at the wrist, on the right side in males and on the left side in females; in the case of eunuchs a nice discretion was necessary in selecting the appropriate side. The various pulses were likened to the motions of animals such as the serpent, the frog, the swan, and the peacock, etc. Diseases were attributed to eccentricities of the three humours, namely air, bile, and phlegm, which were duly reflected in the pulse. Thus in a disturbance of the phlegm, the pulse was slow and heavy like the motion of a swan or peacock, while in a distrubance of the air, the pulse was like the motion of a serpent. If both humours were at fault; the pulse exhibited both motions in sequence. If the two motions occurred in regular succession, the disease was easily curable; but if they occurred irregularly, cure was likely to be difficult. The pulse was particularly important in fevers of which there were many varieties, but it was also useful in other diseases. For example, in diabetes (honey urine) the course of the pulse presented occasional knots, and in piles it was depressed in the middle, quick, and zigzag. Thus in India, as in China, sphygmology was practiced in a purely empirical fashion and while there is no reason to suppose that this wisdom of the East was influenced by Greek ideas, there may have been some link between the two via Persia. In Alexander's expedition to India, it is said that the 


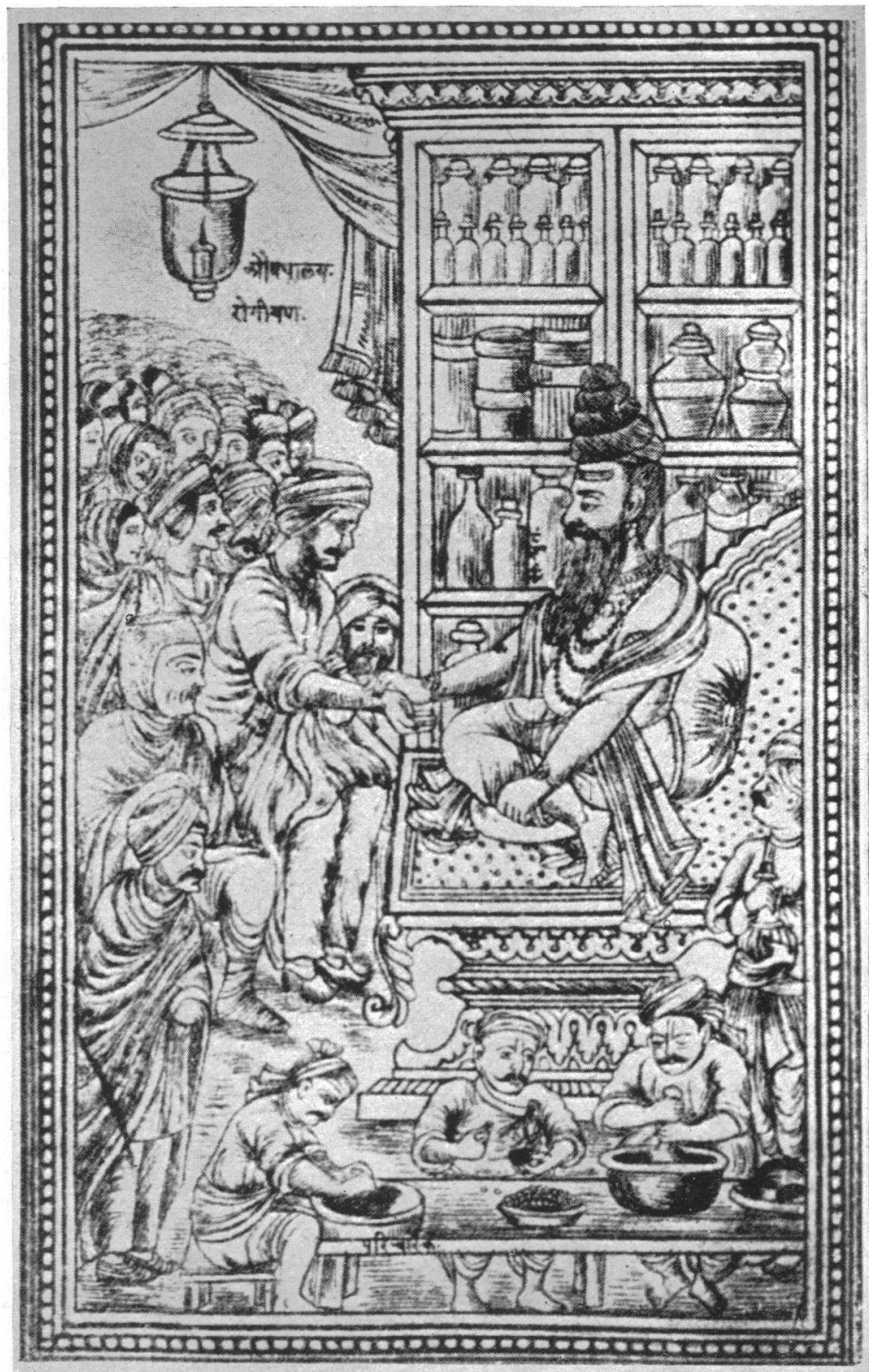

FIG. 2.-A consultation by Susruta, the Hindu physician, who is portrayed feeling the pulse. From Castiglioni's L'Histoire de la Medecine, Editions Payot, Paris.

Indian physicians were more skilful than the Grecian in curing snake bites in the troops, so that some interchange of medical ideas probably occurred.

\section{GreEK SPHYGMOLOGY}

It is unlikely that Hippocrates actually felt the pulse at the wrist, though he observed the beating of the temporal arteries, and Ozanam cites several references to the pulse from the Hippocratic works. The important authorities on the pulse before Galen's time were Herophilus, Archigenes, 
and Rufus of Ephesus. Though the treatise on the pulse of Rufus is preserved, we are mainly dependent on citations by Galen and later writers for our knowledge of pre-Galenic sphygmology.

Herophilus (4th century B.C.), an Alexandrian physician and anatomist and a contemporary of Aristotle, is regarded as the creator of ancient sphygmology. He believed that a knowledge of both music and geometry was necessary in order to interpret the pulse, and he paid great attention to its rhythm or cadence which he likened to musical time and measures of verse, a method later revived by Marquet in 1747. By rhythm was meant the relative duration of arterial expansion (diastole) and the pause (systole) (see p. 427). In old age, he found the systole five times as long as diastole, whereas at birth they were of equal duration. He recognized four main qualities of the pulse, namely its size, frequency, force, and rhythm, and he is said to have timed the pulse by a clepsydra or water clock.

Archigenes (1st century A.D.) was born in Syria and practised in Rome, and his treatise on the pulse was evidently regarded as important by Galen, who cites it repeatedly. According to Daremberg, he described ten varieties of pulse as determined by (1) the quantity of diastole, (2) the quality of the movement, (3) the intensity of the force, (4) the quantity of the beat, (5) the duration of the pause, (6) the consistency of the artery, (7) the equality or inequality, (8) regularity or irregularity, (9) fullness or emptiness, and (10) the rhythm. It should be pointed out that equality or inequality applied to the individual beat.

Rufus of Ephesus (2nd century A.D.) wrote an excellent treatise on the pulse which was published in early Latin editions of Galen, but it was identified by Daremberg as pre-Galenic and attributed by him to Rufus. The French translation was first published in 1845, and later was included in Daremberg's edition of the works of Rufus (1879).

Rufus recognized that the heart was the cause of the pulse which he defined as the diastole and systole of the heart and arteries which alone have a sphygmic property. He also recognized that the arterial pulse coincided with emptying of the heart and filling of the arteries. He dealt with various kinds of pulse according to age, in fever, in diseases, and finally with the pulses named by ancient writers. At birth, he found the pulse small like a needle-point, so that it was impossible to recognize systole and diastole. He remarked that the pulses of pleurisy and pneumonia differed so little that only a physician of great experience could make the distinction. He recognized the size, quickness, fullness, and rhythm of the pulse. He distinguished the quick pulse that recedes rapidly from the finger (collapsing) from the frequent or as we say rapid pulse, a distinction followed by Galen and subsequent writers. Rufus mentioned a number of the classical pulses such as the myurus, the dicrotic, the caprizans, the formicans, and the vermiculans, all of which Galen described in detail later.

\section{GaLEN}

Galen (A.D. 131-200) (Fig. 3) must rank as the foremost spygmologist of antiquity, indeed of all time, not merely because he wrote more books on the subject than anyone else before or after him, but because his teaching on the pulse dominated clinical practice for about sixteen centuries, and until long after Harvey's time. He enjoyed an enormous practice in Rome where he was famed for his skill in interpreting the pulse, and where it was said that Apollo prophesied through the mouth of Galen. It seems unlikely that his office of surgeon to the gladiators at Pergamos was conducive to a study of the pulse, and he probably acquired his knowledge of it during his years of study in medical centres in the middle east, especially at Alexandria, the traditional birthplace of the sphygmical art. Some of his books on the pulse, notably his commentaries on Archigenes, have been lost, but the following 18 books which have been preserved are regarded as authentic. (For bibliography of the Latin editions of Galen, see Campbell, 1926.)

(1) Treatise on the Pulse for Beginners.

(2) Four Books on the Varieties of the Pulse.

(3) Four Books on the Diagnosis of the Pulse. 
(4) Four Books on the Causes of the Pulse.

(5) Four Books on Prognosis by means of the Pulse.

(6) Synopsis of sixteen Books on the Pulse.

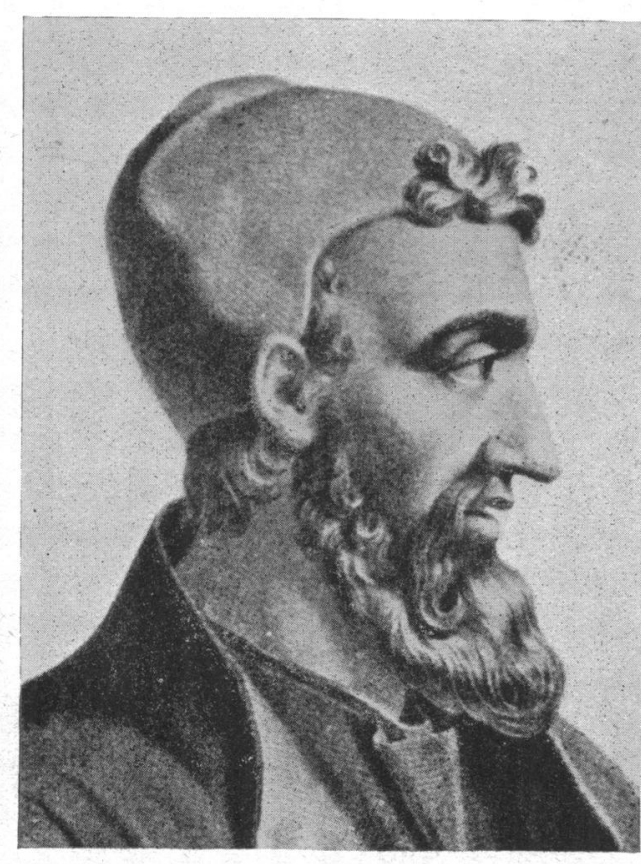

FIG. 3.-Claudius Galenus (A.D. 131-200). The greatest sphygmologist of antiquity and author of 18 books on the pulse. Reproduced from Hamilton Bailey and W. J. Bishop's Notable Names in Medicine and Surgery. London, H. K. Lewis, 1944.

According to Brock, Galen was a master of language, using a highly polished variety of Attic prose with a precision that is difficult to reproduce in other tongues, and this may explain the obscurity of some of his theories of the pulse to those of us who are not Greek scholars. No translation of the Greek or Latin versions of Galen's books on the pulse into a modern tongue has been published, though Broadbent gave extracts from the treatise for beginners (Libellus de Pulsibus ad Tirones), of which I possess Latin editions of 1531 and 1575 , and a complete translation kindly made for me by Dr. Worms and Mr. Rasp from the Greek and Latin texts of the Kühn edition. Fortunately, we may consult the works of scholars of the past who have especially studied Galen' pulse doctrines, the most valuable of which are Paulus Aegineta On The Pulse from the Works of Galen, translated by Francis Adams with commentary, Daremberg's notes appended to the treatise of Rufus, LeClerc's Histoire de la Médicine (1723), Wetch (1770), Gruner (1775), Menuret (1768), and Ozanam (1886).

Galen defined the pulse as a double movement of the artery consisting of expansion or diastole, and contraction or systole, the reverse of modern terminology. He recognized, like Herophilus, that the arterial pulse was dependent on and synchronous with the heart, but he believed that the artery possessed its own pulsific or sphygmic faculty. He regarded arterial diastole as an active expansion by which blood was attracted to the artery, and systole was a more passive state, though he pretended to be able to feel the actual contraction of the artery during its systole. He recommended feeling the pulse at the wrist as most convenient, and he frequently emphasized the importance of feeling the pulse in health so as to have its normal qualities in mind when judging the pulse in the sick. He described at length the variations of the pulse due to age, sex, season, country, sleep, pregnancy, exercise, bathing, food, and wine. The more important kinds of pulse were as follows.

(1) The quick or slow pulses, by which was meant the quickness of arterial expansion during a single beat. Thus the pulsus celer corresponds to our collapsing pulse, and the pulsus tardus to our sustained pulse of aortic stenosis. Between these two extremes was a pulse of intermediate kind called moderate.

(2) As the artery is extended in all directions, so it has length, breadth and depth. A pulse that is at the same time long, deep and broad is a large pulse, and one that is short, shallow and narrow a small pulse. In the case of each dimension, between the two extremes is a pulse of moderate grade, so that there are 27 main varieties of pulse according to dimensions.

(3) The beat may be strong, weak, or moderate.

(4) The arterial wall may be hard or soft.

(5) The artery may be full or empty. In a full pulse the artery feels completely filled with fluid; 
in an empty pulse the artery feels as if filled with bubbles of air so that the finger sinks into empty space.

(6) The frequent or infrequent pulses. This was judged by the duration of the interval between the beats; for of course Galen had no pulse watch.

(7) The rhythm or cadence of the pulse, related to the duration of systole and diastole, following the ideas of Herophilus. Thus the pause might be two to four times as long as the expansion.

(8) The equality (evenness) or inequality. It is extremely difficult to follow all Galen's subtle distinctions in this respect, but he recognized an inequality of movement in a single beat or in successive beats. The pulsus myurus consisted of a series of beats of diminishing intensity, likened to the tail of a rat; if the pulse faded completely, it was called a failing myurus, if it gradually reappeared, a recurrent myurus. This description suggests sinus arrhythmia, but against such a view is the grave prognosis accorded it by Galen. Of the various pulses exhibiting inequality of the individual beat, we may mention the dicrotic, consisting of a double beat, and the pulsus caprizans, named by Herophilus, which resembled the leap of a goat or of a gazelle (pulsus gazellans of Avicenna). As the gazelle is said to leap up, pause in the air, and then to take a swifter and mightier spring, so the expanding artery pauses, then makes a swifter and larger movement. In studying the pulsus caprizans, I have often watched the goat's peculiar leap, as Galen did, on roadsides in the Middle East, but I confess that these nature studies have been less helpful than the graphic description of this pulse given by Struthius and to be mentioned later (see Fig. 4).

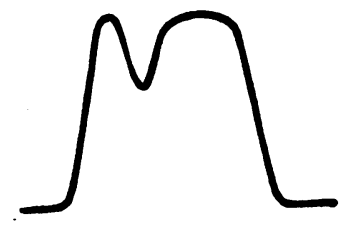

A

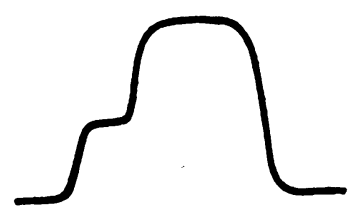

B

FIG. 4.-The pulsus dicrotus (A) and the pulsus caprizans (B) represented after the description by Struthius.

In the spasmodic pulse, the artery feels like a stretched cord or string, and we still hear the expression "thready pulse." The undulant pulse gives impression of waves rolling down the artery, the vermicular pulse of worms, and the formicant of ants; the latter represents the extreme grade of this variety of pulse which marked great feebleness of the vital faculty and, in fevers, presaged a fatal ending.

In the intermittent pulse, one or more beats are completely missing; and in the intercurrent there is an accessory beat or, as we should say to-day, an extrasystole. Galen took a most serious view of the intermittent pulse and he had never seen recovery in a case where two beats were missing. The pulsus serratus or saw-like pulse was an unequal pulse encountered in inflammatory states, and the convulsant pulse a dangerous kind if it followed dysenteric evacuations.

Galen originated the conception of the organic pulses, later elaborated by Actuarius, de Bordeu, and others, by which each organ imparted its personality to the pulse, and by this method he was able to diagnose stomach trouble in the Emperor. He also invented the critical pulses, later revived by Solano, successfully predicting a crisis in the form of epistaxis from the pulse of a young senator.

Galen's sphygmology exemplifies his mania for system and his extreme subtlety of mind, not to mention his verbosity, which involved him in a maze of obscure theory and led him to wander far from the path of clinical observation. As he well remarked, it requires the whole life of a man to acquire a complete knowledge of the pulse and, after perusing his treatises, we may well feel with Hippocrates that art is long and life short. 


\section{SPHYGMOLOGY AFTER GALEN}

Though it is unlikely that the average physician really mastered Galen's pulse doctrines, they nevertheless prevailed throughout the Middle Ages when the most important authorities on the pulse were the Canon of Avicenna (10th century A.D.), Actuarius (11th century A.D.) and the famous poem on the pulse by Gilles de Corbeil (12th century A.D.) of the School of Salerno. At

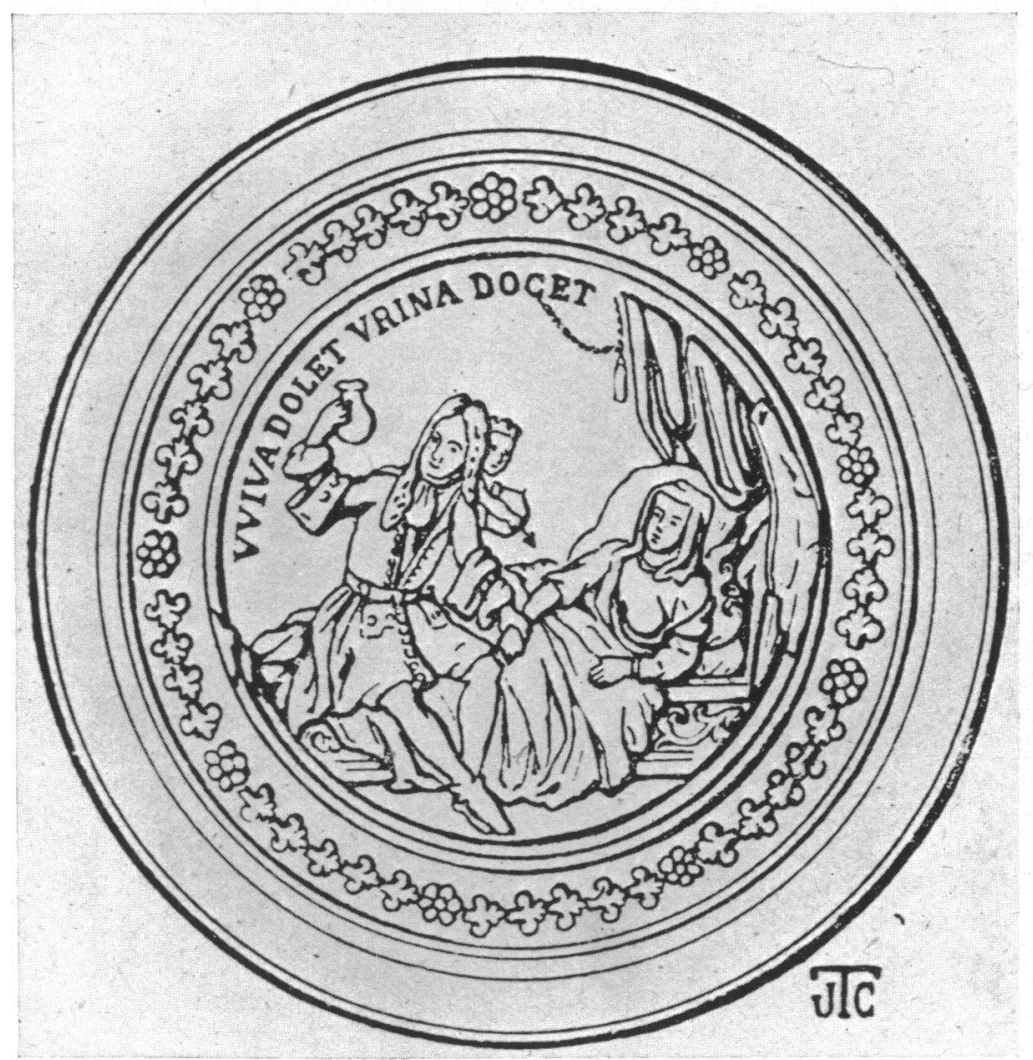

Fig. 5.-Woodcut representing physician feeling the pulse and inspecting the urine in a case of mal d'amour (chlorosis or green sickness); note the cupid with arrow behind the doctor's head. From Vieillard, L'Urologie et les Médecins urologues, Paris, 1903.

this period, most sphygmologists were also urologists, basing their diagnosis partly on the pulse and partly on an inspection of the urine. They are often portrayed with one hand on the pulse and the other holding aloft a flask of urine (Fig. 5), and many experts on the pulse also wrote treatises on the urine, for example, Gilles, Bellini, and Fludd. Avicenna, physician to the Bagdad Hospital, added to Galen's assortment the twisted, knotted, and tremulous pulses, and a new myurus in the form of the tail of a mole. He also forecast the sex of an unborn child from the pulse of a pregnant woman; if her right pulse was the stronger and faster, it indicated a boy.

By far the most important work on the pulse between Galen and Harvey's time was the Ars Sphygmica of Joseph Struthius, first published in 1540, and of which 800 copies were sold in a single day at Padua. Several later editions were called for and my own copy is that of 1602, with an introduction by Bauhin.

Struthius was a Pole, educated at Cracow and later at Padua, where he became a Professor of Medicine at the early age of 25 . Later he returned to Poland, where he enjoyed great fame as a physician, being summoned to Constantinople to see the Sultan, and invited to Madrid as Physician 


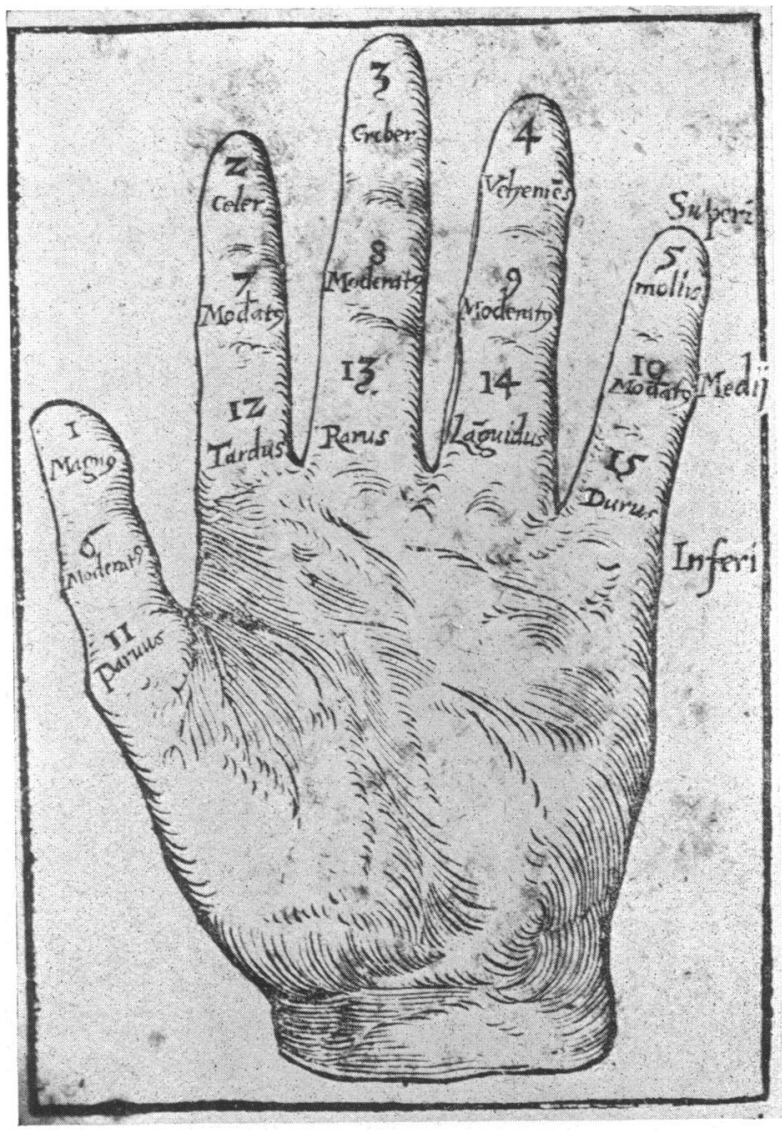

Fig. 6.-Mnemonic for the five simple pulses from the Ars Sphygmica of Struthius. Starting from the thumb, large and small pulses, quick and slow, frequent and infrequent, strong and weak, soft and hard; moderate represents an intermediate grade in each case.

to the Court. His work on the pulse consists of five books written in Latin and therefore heavy reading to-day, but Bugiel's careful analysis of them in his life of Struthius is a useful guide.

Struthius made a profound study of Galen's works on the pulse which he was able to read in the Greek, and he also cited the works of Archigenes, Avicenna, Erasistratus, Herophilus, Oribasius, and other authorities. He simplified and clarified Galen's sphygmology, giving simple tables and schemata, and a useful mnemonic in the form of a hand, each digit of which represented one of the five simple pulses (Fig. 6), namely large or small, quick or slow, frequent or infrequent, strong or weak, soft or hard; allowing for an intermediate grade between the two extremes in each case, we have 15 simple pulses in all. There were many composite pulses, not all of which were actually encountered in practice.

He studied the pulse wave by placing a leaf on the artery and watching its vibrations, and he was the first to represent the pulse graphically in a form comparable with a sphygmographic tracing (Fig. 7). His description of the various classical pulses is easier to follow than Galen's. For example, a warrior is attacked by two adversaries; one plunges his sword into the thigh down to the bone, then withdraws it moderately, and finally replunges it anew to the bone-this is the pulsus dicrotus. The other plunges his sword into the thigh muscles, pauses, then penetrates violently to 
the bone-this is the pulsus caprizans (see Fig. 4). There is no doubt that Struthius' study of the pulse was based on his own clinical observations as well as on his great knowledge of ancient writers; and Gruner, the first historian of the pulse, advised all who wished to understand Galen to have Struthius's book in their hands.

Mention must be made of Robert Fludd's Pulsus (1631), a mixture of ancient sphygmology and abstruse metaphysics which illustrates the influence of alchemy on medicine at this period. Fludd, who also styled himself Robertus de Fluctibus, was an alchemist and a leading exponent of the Paracelsian sect known as Rosicrucians. His Pulsus was published in Frankfort by William Fitzer, the first printer of de Motu Cordis, and Weil (1944) has suggested that Fludd may have persuaded Harvey, his fellow student at Padua, to patronize Fitzer. Fludd's treatise on the pulse, written in Latin, abounds in the mystical absurdities of his peculiar system and contains many extraordinary illustrations (see Fig. 8).

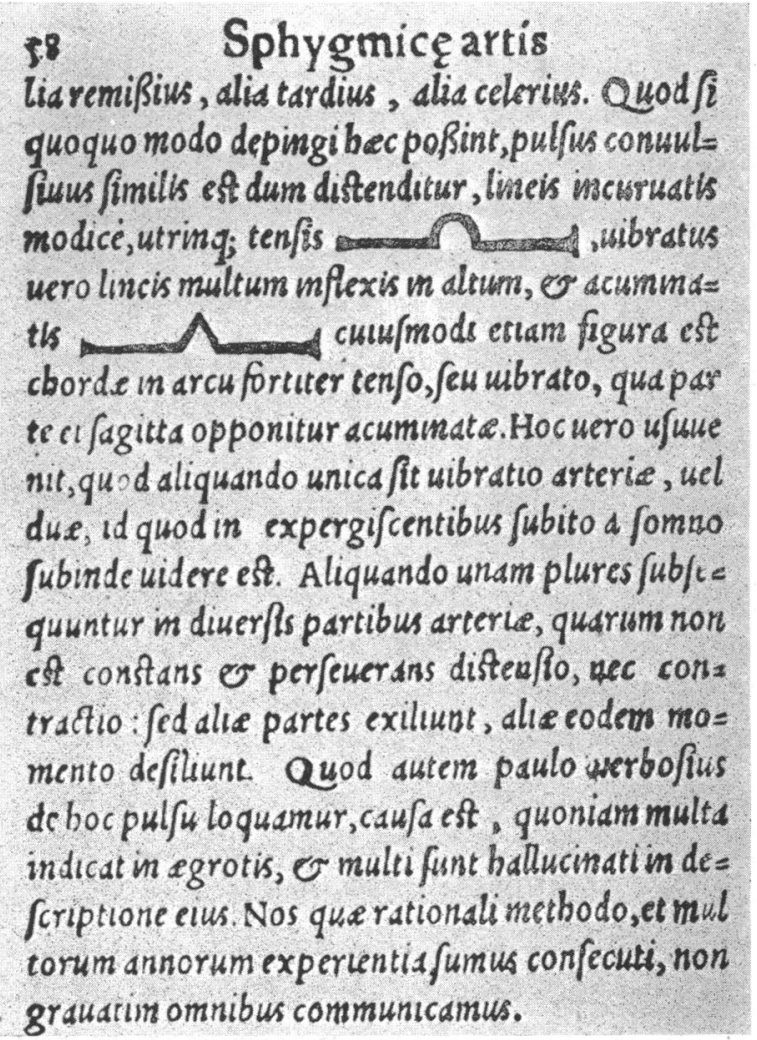

Fig. 7.-The earliest graphic representation of the pulse by Struthius in the Ars Sphygmica.

Revival of Galenic Sphygmology during the 18Th Century

Over a hundred years after the discovery of the circulation, a remarkable revival of the ancient sphygmical art occurred in Europe. Curiously enough, it was started by an unknown Spanish practitioner, Francisco Solano de Luque, of Antequera in Southern -Spain. Solano was an indifferent scholar and held no appointment of importance, but he devoted himself assiduously to the study of the pulse for many years and, in 1731, published a large folio volume entitled Lapis Lydius Apollonis (The Touchstone of Apollo) in which he described his new method of predicting crises by the pulse. This was a badly written book of which few copies seem to have been printed, and 
nothing more might have been heard of it had not a copy fallen into the hands of James Nihell, an Irish physician employed at Cadiz. Nihell, surprised at what he read, journeyed to Antequera where he spent two months investigating Solano's methods, to which he became completely converted. Finding the new discoveries neglected in Spain, he published an account of them in London entitled New and Extraordinary Observations concerning the Prediction of various Crises by the Pulse (1741), which book was translated into Latin by Northwyk (1746) and into French by Lavirotte (1748). With Nihell's help, Solano revised his manuscripts which were republished in Spanish after his death, and the portrait in Fig. 9 is reproduced from a posthumous edition of 1787.

It is unlikely that Solano was well acquainted with Galen's works and he probably rediscovered rather than revived the critical pulses. He believed that, in acute disease and fevers, nature attempted to expel the morbid humours by means of profuse diarrhœa, sweating, polyuria, etc., and that this struggle was reflected in the pulse, from which the nature of the forthcoming crisis could be predicted. The dicrotic pulse indicated a critical epistaxis, the intermittent pulse critical polyuria or diarrhœa; intermittence with tension indicated both vomiting and diarrhœa; with 
softness, polyuria and diarrhœa; the pulsus inciduus indicated critical sweating, and so forth. Once proclaimed by Nihell and his translators, Solano's discoveries attracted attention throughout Europe, and in England treatises on the subject were published by Malcomb Fleming (1753) and by Daniel Cox (1758), physician to the Middlesex Hospital, who wrote on the intermittent pulse.

The next figure in this revival is Théophile de Bordeu of Montpellier whose Researches on the Pulse first appeared in 1756; my own copy dated 1758 comprises four volumes! Bordeu revived the idea of the organic pulses. First, he classified the pulse into superior and inferior varieties corresponding to organs above and below the diaphragm respectively; the superior pulses were subdivided into pectoral, guttural, nasal, and so on; the inferior into gastric, intestinal, renal, uterine and such like types. When more than one organ was affected, a composite pulse resulted.

Shortly afterwards, Henri Fouquet, also of Montpellier, published his Essay on the Pulse (1767), in which he contrived to combine the organic pulses of Bordeu with the critical pulsès of Solano, 
so that his sphygmology became as intricate as Galen's. His book is notable for some remarkable figures of the various organic pulses as perceived by the finger (Fig. 10). I possess an edition of Fouquet's book published as late as 1818, showing that it remained popular even fifty years after its appearance. The last book appertaining to this revival was Rucco's Science of the Pulse (1828) published in London in two volumes and dedicated to Sir Henry Halford, President of the

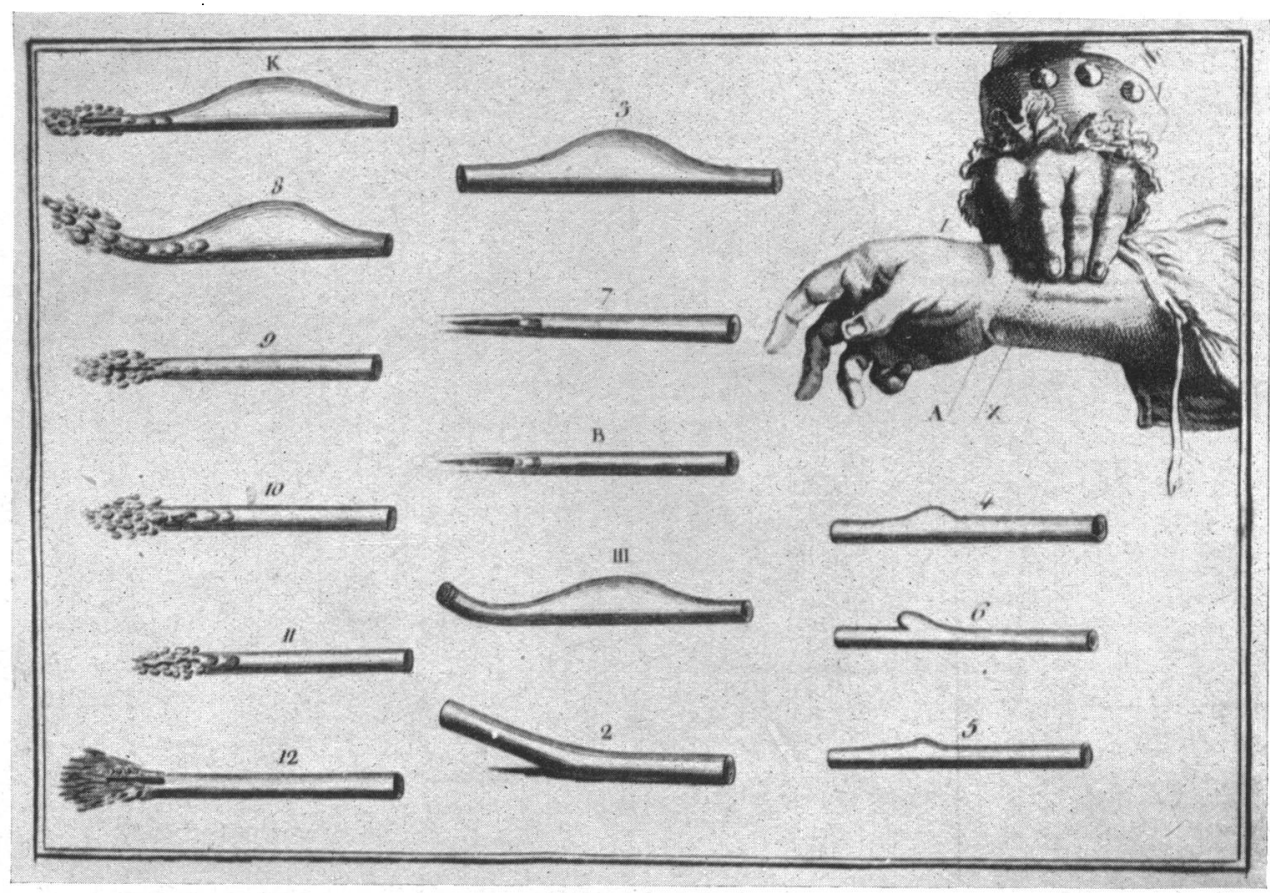

FIG. 10.-The organic pulses of Fouquet. (1) Method of palpating the pulse, (2) Capital pulse, (III) Guttural, (3) Pectoral, (4) Gastric, (5) Hepatic, (6) Splenic, (7) and (B) Intestinal, (8) Nasal, (10) and (11) Uterine, (K) Hæmorrhoidal. From Fouquet's Essai sur le Pouls, edition 1818.

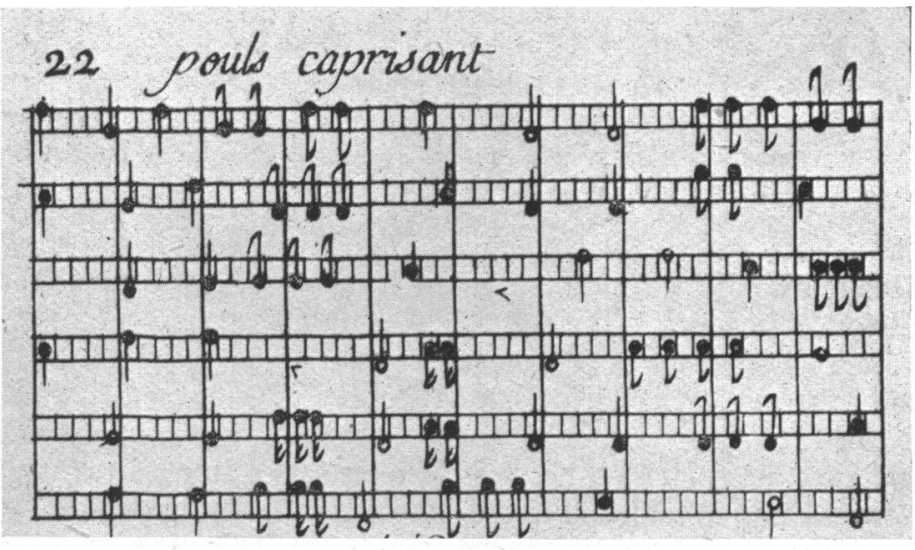

Fig. 11.-The Pulsus Caprizans in musical notation from Marquet. A crotchet indicates the natural pulse, a minim the large pulse, a quaver the small pulse, and a semi-quaver the vermicular pulse. Five vertical lines indicate the normal interval between beats. 
Royal College of Physicians. Rucco was an Italian practising in Golden Square, and his book contains a lengthy and uncritical account of the ancient pulse doctrines from Galen to Solano.

Mention must be made of the Nouvelle Méthode facile et curieuse pour Connoitre le Pouls par les Notes de la Musique by Marquet of Nancy (1747) and its second edition with commentary by Buchoz of Metz in 1769. Marquet returned to the ideas of Herophilus and devised a special musical notation to record the pulse, each of the classical varieties being portrayed in musical format (see Fig. 11). He stated that those accustomed to play on the lute made the best judges of the pulse!

Lastly, and in a rather different category, are the works of William Ewart, well known for his signs of pericardial effusion. Ewart's work was a revolt against the sphygmograph and a last attempt to preserve the tactus eruditus of the old-time physicians. Like Galen, he wrote a large treatise on tactile sphygmology (Pulse Sensations, 1894) and a small one for beginners entitled How to Feel the Pulse (1892). He attempted to analyse the tactile impressions produced by the pulse and to correlate them with the sphygmogram and with physiological knowledge. He was an admirer of Fouquet, whom he styled the father of tactile sphygmology.

We might have expected that, with the advent of the sphygmograph,

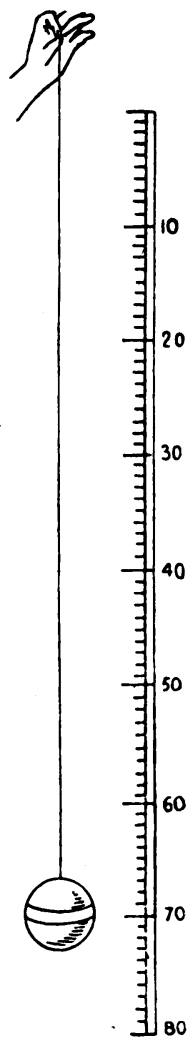
Galen's influence would have been quickly and finally extinguished, but it was not so. For the classical pulses, was, substituted a profusion of sphygmograms which often owed more to the instrument than to the pulse, and which were interpreted quite empirically in relation to the disease rather than in terms of hæmodynamics. Thus Burdon Sanderson in his Handbook of the Sphygmograph (1867) classified the pulse as hard or soft, and amongst the soft pulses we find the pulsus mollis et celer, the undulatory dicrotous pulse, the pulsus mollis et magnus, and the like, each with its own pattern of pulse wave. Similarly, in Lorain's monograph on the pulse (Le Pouls, 1870) we find sphygmograms for every disease from cholera to jaundice, even including one for mercurial poisoning. It was not until the appearance of Mackenzie's Study of the Pulse in 1902 that the Ars Sphygmica faded for ever from clinical medicine.

\section{TIMING the PULSE}

Though Herophilus is supposed to have timed the pulse by a water clock or clepsydra, Kepler the astronomer was the first to record the pulse rate, which he estimated at about one beat a second, commonly 70 a minute in normal men, and 80 in women (Weir Mitchell, 1892.). Galileo (1564-1642) used his own pulse to verify the regularity of the vibrations of a large bronze lamp swaying in the wind, and devised a pendulum clock that did not vary " so much as the beat of a pulse." Galileo's pulsilogon was appropriated by Sanctorius (1561-1636) and consisted of a leaden bullet suspended on a silken cord which was allowed to swing like a pendulum; by shortening or lengthening the cord, its swing was synchronized with the pulse, and the rate or index was read from a scale (Fig. 12). Astonishing as it may seem, nothing further was heard about the pulse rate until the next century, when Sir John Floyer (1709) revived pulse counting. In those days, watches had a single hand marking hours, for which reason Floyer constructed a portable clock which ran for exactly a

Fig. 12.-The Pulsilogon of Sanctorius (from Weir Mitchell). minute. Unfortunately, when tested against his minute glass, the clock was found to run fast, so that he had to correct his pulse counts by adding 5 or 6 beats to the rate given by the clock. He calculated the natural pulse rate as 30 at the North Pole, and 120 at the Equator, and noted the effect on the rate of age, sex, exercise, meals, etc. His book also contained a lengthy review of the Galenic art and of Chinese sphygmology as described by Cleyer. Falconer (1796) gave elaborate tables by which a rise in pulse rate occurring in subjects with naturally fast or slow pulses could be expressed in 
terms of a standard rate of 75 , for the purpose of determining the degree of fever at a time when clinical thermometers had not come into use. Pulse counts were scarcely mentioned in books on the heart published during the first half of the 19th century, and it was not until about 1850 that routine pulse counting with a watch spread to England from Dublin, where it had been introduced by Stokes and Graves.

\section{CONCLUSION}

Against a background of modern knowledge, the Ars Sphygmica seems fantastic and absurd, but not so if we view it in a contemporary setting. Before the discovery of the circulation, no rational basis existed for understanding the pulse; it was only possible to describe what the finger felt and to interpret this empirically in terms of the primitive medical ideas of the time. To liken the pulse to the motion of ants or worms or to the leaping of goats, was perfectly rational and, in the absence of sphygmographs, so was the idea of representing the pulse by musical rhythm. Galen lived in an atmosphere of incessant philosophical controversy and it is not surprising that his ideas on the pulse, some of them quite sound, became obscured in a welter of subtle theory. Did not Galen himself complain-if I do write long books it is not my fault; it is the fault of other people who will write books full of so many wretched arguments. The importance of Galen's work was, first, that it provided a compendium of all that was known or written about the pulse up to his time, and, secondly, that it established the procedure of feeling the pulse at the wrist as a routine method of clinical diagnosis, which it has remained up to the present day.

It was not Galen's fault that science stood still for centuries after his time, but the fault of the subservient spirit of medieval physicians who followed him. By the middle ages, Galenic medicine had grown as old as the Christian faith and was almost as firmly established, but the Greek spirit had disappeared. Things changed slowly in those days and it took a century or more for Harvey's discovery to shake the habit of mind of the practising physician who continued to interpret the pulse according to the precepts of Galen. This time lag between the new discovery and its clinical application was not excessive in relation to the fifteen centuries during which Galenic dogma had reigned unchallenged. It is more difficult to explain the revival of the sphygmical art in the 18th century. Solano was a figure of little importance, but both Bordeu and Fouquet were scholars and teachers of some eminence, who were certainly well acquainted with the Harveian circulation. They themselves did not regard their methods as a revival of the old pulse doctrines, but as new discoveries based on a return to the method of clinical observation, following the example of Sydenham. By ignoring Harvey, they merely succeeded in recreating a sphygmical art in no way better than Galen's. If, in looking back, we remember that the state of affairs to-day is the consequence of that which existed yesterday, then in feeling the pulse we shall not forget that we still owe something to Galen.

We should like to thank Messrs. Editions Payot of Paris for permission to reproduce Fig. 2 from. Castiglioni's L'Histoire de la Medecine, and Messrs. H. K. Lewis \& Co., of London for permission to reproduce Fig. 3 from Notable. Names in Medecine and Surgery, by Hamilton Bailey and W. J. Bishop, and Messrs. R. de Rudeval of Paris, for permission to reproduce Fig. 5 from Viellard's L'Urologie et les Medicins Urologues.

\section{REFERENCES}

Broadbent, W. H. (1890). The Pulse. London.

Bordeu, Th. de. (1768). Recherches sur le Pouls par rapport aux Crises. 2nd ed., Paris.

Bugiel, V. (1901). Un célèbre Médecin Polonais au XVI Siècle, Joseph Struthius. Paris.

Campbell, D. (1926). Arabian Medicine. Vol. 2, London. 
Cox, D. (1758). Observations on the Intermitting Pulse. London. (1766). Observations on the Intermitting Pulse. French Translation, Amsterdam.

Ewart, W. (1892). How to Feel the Pulse, Practical Hints for Beginners. London. (1894). Pulse Sensations. London.

Falconer, W. (1796). Observations respecting the Pulse. London.

Fleming, M. (1753). De Francisci Solani inventis circa arteriarum Pulsum, etc. London.

Floyer, Sir J. (1707). The Physician's Pulse-Watch. London.

Fludd, R. (1631). Pulsus, seu Nova et Arcana Pulsuum Historia. Frankfort.

Galenus, Claudius (1824). Opera Omnia, edition Kuhn. Leipzig.

- (1531). Commentariolus de Pulsibus ad medicinae Candidatos. Joanne Guinterio Andernaco interprete. Paris.

- (1575). L. Rogani-in Galeni libellum de Pulsibus ad Tyrones commentarius. Venice.

Gruner, C. G. (1775). Semiotice physiologicam et pathologicam generalem complexa. Halle.

Gupta, K. N. N. S. (1901). The Ayurvedic System of Medicine. Calcutta.

Halde, J. B. du. (1735). Description de L'Empire de la Chine. Vol. 3. Secret du Pouls (Ouang-chou-ho). Paris.

Lavirotte (1748). Observations nouvelles et extraordinaires sur la Prediction des Crises par le Pouls. Paris.

LeClerc, D. (1723). Histoire de la Médicine. Amsterdam.

Lorain, P. (1870). Le Pouls. Paris.

Marquet (1747). Nouvelle Méthode facile et curieuse pour Connoitre le Pouls par les Notes de la Musique. Nancy.

Marquet and Buchoz (1760). Nouvelle Méthode facile et curieuse pour Connoitre le Pouls par les Notes de la Musique. 2nd ed., Amsterdam.

Menuret (1768). Nouveau Traité du Pouls, Amsterdam.

Mitchell, S. Weir (1892). The Early History of Instrumental Precision in Medicine. New Haven.

Nihell, J. (1741). New and Extraordinary Observations concerning the Prediction of various Crises by the Pulse. London.

Noortwyk, W. (1746). Novae raraeque Observationes circa variarum Crisium Praedictionem ex Pulsu. Amsterdam.

Ozanam, Ch. (1886). La Circulation et le Pouls, Paris.

Paulus Aegineta (1879). The Seven Books of Paulus Aeginata. Trans. by F. Adams. Vol. I, p. 202, On the Pulse from the Works of Galen. London.

Rucco, J. (1827). Introduction to the Science of the Pulse. London.

Rufus of Ephesus (1847). Traité sur le Pouls. Translated by Daremberg, Paris.

- (1879). Oeuvres de Rufus. Translated by Daremberg. Paris.

Sage Kanad (1891). Science of Sphygmia. Sanskrit with English translation by Gupta. Calcutta.

Sanderson, J. B. (1867). Handbook of the Sphygmograph. London.

Solano de Luque, F. (1787). Observaciones sobre el Pulso, opera postuma. Madrid.

Struthius, Joseph (1602). Ars Sphygmica. Bale. (First edition 1540.)

Weil, E. (1944). William Fitzer, the Publisher of Harvey's de Motu Cordis, 1628. London, The Bibliographical Society.

Wetch, J. J. (1770). Medicina ex Pulsu. Vienna.

Wise, T. A. (1845). Commentary on the Hindu System of Medicine. Calcutta. 